\title{
BOLAÑO INTERNACIONAL \\ ALGUNAS REFLEXIONES EN TORNO AL ÉXITO INTERNACIONAL DE ROBERTO BOLAÑO
}

\section{Ignacio Echevarría}

\begin{abstract}
Resumen: Tomando como punto de partida el ensayo Bolaño traducido: Nueva literatura mundial, de Wilfrido $\mathrm{H}$. Corral (Madrid, Ediciones Escalera, 2011), este artículo propone una reflexión sobre el éxito de Bolaño en el marco de lo que cabe entender por "literatura mundial", con especial atención a su recepción en Estados Unidos. La rapidez y la unanimidad con que Bolaño ha sido internacionalmente aplaudido, invita a considerar, sirviéndose de su caso, los alcances del concepto mismo de "literatura mundial", y a observar cómo actúan sus mecanismos de consagración. La condición del arte en una cultura a la que se ha sustraído todo horizonte de posteridad, así como la derrota de las utopías que encarnaron la revolución y la vanguardia, se encontrarían, según el autor, en la base de la fortuna de la obra
\end{abstract}

IgNACIO EchEVARRía (Barcelona, 1960). Licenciado en Filología por la Universidad de Barcelona. Editor y crítico literario, ha estado al cuidado de la edición póstuma de algunas obras de Roberto Bolaño (Entre paréntesis, $2666 \mathrm{y}$ El secreto del $\mathrm{mal}$ ). Entre sus publicaciones se cuenta el volumen Desvíos: Un recorrido crítico por la reciente narrativa latinoamericana (Santiago, Ediciones Universidad Diego Portales, 2006). 
de Bolaño, que en sus libros tematiza recurrentemente estos dos asuntos.

Palabras clave: Roberto Bolaño, literatura latinoamericana, literatura internacional.

Recibido: abril 2013; aceptado: mayo 2013.

\section{BOLAÑO INTERNATIONAL WRITER: SOME REFLECTIONS ON ROBERTO BOLAÑO'S GLOBAL SUCCESS}

Abstract: Taking as a starting point Bolaño traducido: nueva literatura mundial, by Wildrido H. Corral (Madrid, Ediciones Escalera, 2011), this article proposes a reflection on Roberto Bolaño's success in the context of what has come to be referred to as "global literature", with a focus on the reception encountered by his books in the United States. Bolaño has been rapidly and unanimously internationally acclaimed. This prompts us - says Ignacio Echevarría - to consider the implications of the very concept of "global literature", and to analyze the process leading to a topwriter status. The situation of art in a culture deprived of any horizon of posterity, as well as the defeat of utopias formerly incarnating revolution and vanguard, two recurring themes in Bolaño's books, would be, according to Echevarria, the cornerstone of Bolaño's success.

Keywords: Roberto Bolaño, Latin American literature, global literature.

Received: April 2013; accepted: May 2013.

Para Rubén Ángel Arias, que va camino de ser quien sabe más, y mejor, de Roberto Bolaño

$\mathrm{E}$ rápido, casi súbito y sin duda espectacular aupamiento de Roberto Bolaño al estrellato literario internacional es un fenómeno al que se han buscado toda suerte de explicaciones. Al parecer, no basta con la más obvia y concluyente, a saber: la que señala a Bolaño como un escritor excepcional, muy por encima de la media, con una infrecuente capacidad de conectar con lectores de todo tipo, muy en particular los más jóvenes, aun siendo dueño de un estilo y de un mundo marcadamente propios.

La imposibilidad cada vez mayor de objetivar y articular baremos conforme a los cuales convenir que un escritor posee cualidades 
que lo elevan por encima de otros escritores también excelentes, hace que resulte cuestionable o cuando menos incierto invocar como explicación única de un fenómeno como el de Bolaño el criterio de calidad. A ello hay que añadir la suspicacia que, en una cultura mediática, suscita todo fenómeno de aceptación masiva, aun si se produce - como en el caso de Bolaño - con el beneplácito de la crítica más exigente.

Un prurito quizá romántico de aislamiento, de incomprensión, de pureza mueve a muchos a revolverse instintivamente contra todo lo que se presenta investido de moda, envuelto en un éxito más o menos unánime, tanto más si ese éxito se traduce, como en el caso de algunos de los libros de Bolaño - no todos, ni mucho menos-, en un éxito comercial.

Bolaño mismo participaba de la muy extendida superstición contra la fama. Borges dijo de ésta que era un malentendido. Dijo también que conllevaba siempre una simplificación. Roberto Bolaño, mucho más radical que Borges, dijo que "la fama es una estupidez, sobre todo referida a la literatura". Dijo también: "En el momento en que llegamos en la literatura al todo vale, a una especie de democracia mediática en donde todo es bueno, en donde todos podemos tener nuestros quince minutos de fama, pues ahí se acaba la literatura y se acaba, en gran medida, porque les estamos dando mierda a los lectores"

Nadie, ni siquiera el más escéptico respecto a la valía de la obra de Bolaño, sostiene que haya dado mierda a los lectores. Pero no son pocos los que piensan que su éxito se beneficia de esa "democracia mediática" de la que él mismo habla; que estamos asistiendo a los "quince minutos de fama" (lo mismo da que sean quince años, a los efectos) que corresponden a un escritor como él, sobre el que - con independencia de su calidad - confluyen una serie de circunstancias más o menos fortuitas (como su muerte temprana, asociada a las secuelas de una juventud salvaje) que habrían determinado que los focos de la celebridad se posen sobre su figura y su obra.

"La reputación - escribe Vicenç Furió, autor de un libro notable sobre la cuestión: Arte y reputación. Estudios sobre el reconocimiento

${ }^{1}$ La primera de las dos declaraciones la hizo en el marco de una entrevista de Felipe Ossandón para el diario El Mercurio, Santiago, 14 de febrero de 2003; la segunda, en el de una entrevista de Melanie Jösch para el diario La Tercera, Santiago, 25 de febrero de 2000. Los dos pasajes están recogidos en Bolaño por sí mismo, edición de Andrés Braithwaite, 2006, pp. 96 y 97, respectivamente. 
artístico, 2012- es una construcción social. Cuando hablamos del prestigio de los artistas o de la calidad de sus obras aludimos a un tipo de apreciación que no sólo es históricamente variable, sino que, aunque nos refiramos a una época determinada, tampoco se trata de una opinión unánime. La reputación artística, entendida como la consideración del prestigio, excelencia o estima que se tiene por el arte y sus creadores, es una atribución de valor que se configura socialmente por la acción de diversos agentes e instancias de reconocimiento, cada cual con sus jueces y criterios [...] El reconocimiento artístico es un proceso que puede analizarse, y con ello deducir que los artistas no alcanzan el éxito o son olvidados de un modo caprichoso o arbitrario. Se observan pautas"2.

Estas pautas son las que, debido precisamente a la velocidad y la unanimidad con que se ha extendido y consolidado, permite observar con particular nitidez el proceso de consagración de Roberto Bolaño en gran parte del mundo; un proceso que alcanza su punto álgido en el gran boom que la figura de este escritor ha conocido en Estados Unidos.

Ha sido allí donde ha terminado de fraguarse lo que bien admite ser llamado "el mito de Bolaño", sustentado sobre todo en sus dos grandes novelas, Los detectives salvajes (2007) y 2666 (2008). Éstas, publicadas en Estados Unidos de forma consecutiva, tuvieron un efecto avasallador. Que de un mismo escritor, recientemente fallecido, llegaran en tan poco tiempo dos obras de este calibre, generó una inmensa curiosidad acerca de su vida y de su personalidad, y esta curiosidad constituyó un caldo de cultivo idóneo para todo tipo de chismes, tergiversaciones e idealizaciones. Como suele ocurrir en estos casos, el periodismo cultural hizo industria de toda noticia - tanto mejor si escandalosarelativa a Bolaño, y el evidente solapamiento del autor con su alter ego narrativo, Arturo Belano, dio pie a todo tipo de proyecciones de la vida de aquél en su obra, y viceversa.

Como sea, el impacto de Bolaño en Estados Unidos supuso su reconocimiento internacional y su ingreso, por la puerta grande, en lo que viene llamándose algo campanudamente "literatura mundial". A esto último - la entronización de Roberto Bolaño en el marco de la "literatura mundial" - ha dedicado el investigador, profesor y ensayista Wilfrido H. Corral el estudio que da pie al presente artículo y que

${ }^{2}$ Vicenç Furió, "Valores relativos, pero no arbitrarios", abril de 2013, pp. 3-4. 
lleva por título Bolaño traducido: nueva literatura mundial (Madrid, Ediciones Escalera, 2011).

Wilfrido Corral (a quien quiero agradecer las amigables referencias que hace a mí en su libro) ha tenido el acierto de escoger un tema lleno de interés y de posibilidades, si bien los resultados de su trabajo mueven a pensar que ha obrado con alguna precipitación, y que ha dejado pasar la oportunidad —al menos de momento — de llegar a conclusiones más significativas. Uno no puede dejar de pensar que, con un poco más de tiempo y decantación, con un poco más de método y de perspectiva, se podrían haber alcanzado sobre el asunto vislumbres mucho más útiles y relevantes.

Así y todo, Bolaño traducido contribuye a delimitar y a roturar el campo escogido, y a poner en órbita algunas preguntas oportunas, no solamente relativas a la fortuna internacional de Bolaño, sino también, y antes de eso, a la pertinencia — para el caso de Bolaño como para cualquier otro- de esa categoría hoy tan en boga: la de "literatura mundial".

¿Qué es la literatura mundial? Wilfrido Corral —y ésta la primera y quizá determinante debilidad de su libro - no se ocupa de procurar una definición suficiente de este concepto. De hecho, resulta difícil, a partir de la lectura de Bolaño traducido, hacerse una idea ni del contenido ni de los alcances de esa "nueva literatura mundial" a la que el subtítulo alude. Se superponen al respecto afirmaciones demasiado vagas, tales como, muy al principio, esa conforme a la cual la "nueva literatura mundial" no sería "la misma en que creían nuestros abuelos o padres académicos, sino la que reconstruye modelos de identidad y patrones novelísticos sin límites, desde una exterioridad nebulosa, liberada de dependencias políticas y nacionales" (p. 9). Poco después, el mismo Corral deja entrever las muchas fisuras que una definición de este tipo entraña, y admite que el concepto de "literatura mundial" a veces "sugiere una entidad que trasciende a las literaturas nacionales, y en otros momentos sugiere una suma total de las literaturas de todas las naciones" (p. 14). Para enseguida preguntarse, en relación a los cada vez más extendidos estudios con ambición de comprender la literatura en una escala global: “¿Pero en verdad abarcan aquellos estudios todas las literaturas del mundo? ¿Se sabe a ciencia cierta dónde caben las latinoamericanas en aquel concepto?” (p. 14). 
Para enfrentar estas preguntas Corral pone en juego la vieja noción de cosmopolitismo, que sin embargo despacha inmediatamente arguyendo que se trata de un "concepto académico" demasiado "impreciso y debatido" como para constituir "un registro útil de las interminables relaciones entre el texto original y un 'otro' traducido" (p. 15).

Pero impreciso y debatido, además de vidrioso, es también el concepto de "literatura mundial", como el propio Corral no deja de acusar en el segundo capítulo de su estudio, donde entra a discutir algunos aspectos de libros como Teaching World Literature (2003), de David Damrosch, o América Latina en la "literatura mundial" (2006), colección de trabajos coordinada por Ignacio Sánchez-Prado.

El concepto de "literatura mundial" se remonta, como es bien sabido, a un pasaje de las conversaciones de Goethe con Eckerman fechado a finales del mes de enero de 1827. Allí, discurriendo sobre distintas literaturas del mundo, Goethe expresa su convicción de que "la poesía es un bien común de la humanidad", y añade: "Por eso me gusta echar un vistazo a lo que hacen las naciones extranjeras y recomiendo a cualquiera que haga lo mismo. Hoy en día la literatura nacional ya no quiere decir gran cosa. Ha llegado la época de la literatura universal [Weltliteratur], y cada cual ha de poner algo de su parte para que se acelere su advenimiento".

Pasando por alto el carácter más bien voluntarista de estas palabras, y obviando el contexto en que están pronunciadas, se las ha erigido - como escribe María Teresa Gramuglio - "como la formulación liminar del concepto para la era moderna", dando lugar desde entonces a "interpretaciones de una intensidad casi talmúdica"3.

El concepto, que atravesó los siglos XIX y XX actuando como una especie de trasfondo utópico en el desarrollo del comparatismo, fue revitalizado en 1999 por Pascale Casanova en un libro de amplia y muy polémica resonancia: La République mondiale des Lettres ${ }^{4}$. Desde entonces, la bibliografía en torno a la "literatura mundial" no ha dejado de

3 María Teresa Gramuglio, "El retorno de la literatura mundial", diciembre de 2010-abril de 2011, pp. 11-13. Este artículo sirve de presentación a una traducción de Pablo Gianera de "Filología de la Weltliteratur", breve ensayo con el que Erich Auerbach contribuyó a un volumen de homenaje a Fritz Strich, el autor de Goethe und die Weltliteratur (1946).

${ }^{4}$ Pascale Casanova, La République mondiale des lettres, 1999; La república mundial de las letras, 2001. 
incrementarse exponencialmente, dando ocasión a todo tipo de debates acerca de las implicaciones neocolonialistas, anglocéntricas (o eurocéntricas) y mercantilistas que conlleva.

Dado que buena parte de estos debates han tenido por escenario las universidades estadounidenses, en una de las cuales enseña Wilfrido H. Corral, es una lástima que éste no haya profundizado más en ellos, y que, dado su buen conocimiento del asunto, no haya adoptado una posición más nítida en cuestiones tan decisivas como las hipotéticas diferencias entre literatura mundial (entendida "no como objeto preexistente sino como una construcción que presenta un desafío al trabajo crítico", por decirlo con palabras de la ya citada María Teresa Gramuglio) y globalización cultural (entendida como tendencia a la uniformización derivada de la expansión tanto del mercado como de los medios de comunicación, uno y otros tutelados por las grandes potencias capitalistas).

El fenómeno en torno a Bolaño, debido precisamente a su espectacularidad y a la rapidez con que ha tenido lugar, ofrecía un óptimo hilo conductor para adentrarse en dichos debates. Pero Corral evita hacerlo, y de tal modo que su libro se convierte a momentos, sin él proponérselo, en un testimonio más a favor de quienes, no sin argumentos, sostienen que el concepto de "literatura mundial" enmascara las más veces una selección de las literaturas nacionales realizada con una perspectiva sustancialmente anglocéntrica.

El caso es que Bolaño traducido: nueva literatura mundial no satisface suficientemente las expectativas que un título así despierta. El trabajo de Corral se ciñe, en la práctica, al prolijo escrutinio de cuál y cuánta ha sido la recepción de Bolaño en lengua inglesa. Apenas se da cuenta de la recepción en Latinoamérica y en países como Francia, Alemania e Italia, en los que Bolaño fue publicado con bastante anterioridad a su debut en Estados Unidos.

Corral asume con naturalidad un hecho indiscutible: que ha sido el boom de Bolaño en Estados Unidos lo que lo catapultó a las cimas de la supuesta "literatura mundial". Pero este hecho reclama múltiples puntualizaciones, entre ellas la que recuerda — como no deja de hacer el propio Corral, demasiado pasajeramente- que años antes de su muerte Bolaño ya era un autor internacionalmente celebrado, aplaudido por 
buena parte de la más exigente crítica europea, y venerado por las nuevas generaciones de escritores latinoamericanos.

Una cosa es admitir que, dada la hegemonía del inglés, la traducción a esta lengua de un escritor cualquiera sea condición determinante de su ingreso en el horizonte de lo que quepa entender por "literatura mundial"; y otra cosa es obviar que, para que pueda hablarse propiamente de "literatura mundial", es imprescindible que la recepción de ese mismo autor en el ámbito anglosajón se articule de algún modo con la recepción de ese mismo escritor en otras lenguas.

Al desatender el proceso de recepción de Bolaño en Europa y Latinoamérica, Corral sustrae a sus observaciones, no pocas veces valiosas, de los antecedentes que habían de dotarlas del adecuado relieve.

Lo sorprendente es que al comienzo mismo de su libro, Corral advierte del riesgo que entraña creer que la reputación internacional de Bolaño "se debe a vender su imagen por medio de una mercadotecnia anglosajona", ignorando que fue un autor "reconocido mucho antes y ampliamente en el mundo hispanohablante" (p. 9). Poco después sugiere que la recepción de Bolaño en el ámbito anglosajón no deja de repercutir en el tipo de reconocimiento que recibe en los ámbitos español y latinoamericano. Pero Corral se abstiene, por un lado, de documentar con un mínimo detalle cómo fue la recepción de Bolaño en España y Latinoamérica (con el decisivo punto de inflexión que supuso la concesión del Premio Rómulo Gallegos, poco después del Herralde); y se abstiene también - lo cual hubiera resultado tanto o más interesante - de analizar de qué modo la consagración del escritor en Estados Unidos influyó en la lectura que a partir de entonces se hizo de él en el ámbito hispanohablante.

De haberse ocupado Corral de estas dos cosas, acaso hubiera iluminado mejor cuestiones importantes sobre las que pasa demasiado por encima, como pueden ser los muy distintos alcances de la crítica según se ocupe de un autor cuya lengua y tradición comparte, o se ocupe de un autor foráneo; la resonancia tan diferente que, en un caso o en otro, tiene el éxito de ese autor en una determinada comunidad de lectores; el carácter y los alcances de su influencia en los otros escritores; su capacidad de reinterpretar la tradición o - como hizo Bolaño- de reconfigurar el mapa de la misma; el tipo de clichés que en torno a ese autor generan los distintos contextos nacionales, culturales o idiomáticos; cuáles de esos clichés se repiten en varios o en todos esos contextos; cuáles son los denominadores comunes con que opera la crítica internacional; qué tipo de fraseología se transmite de un país a otro, y por qué 
vías; hasta qué extremo la consagración de un autor en Estados Unidos deforma, subvierte, potencia o reorienta la consideración que hasta ese momento recibía ese autor en su propio país o en su propia lengua...

La difusión de la obra de Bolaño en todo el mundo invita a servirse de ella para ilustrar estas cuestiones, e indagar en sus consecuencias. Invita asimismo a preguntarse por el grado de impermeabilidad de la cultura anglosajona a otras culturas (en particular la hispanoamericana) y, a la inversa, a preguntarse también por el grado de permeabilidad de esas otras culturas a la cultura anglosajona.

$*$

Para responder la primera de estas preguntas sería interesante averiguar de qué modo la buena recepción de Bolaño en países como Francia y Alemania, que son potencias culturales, influyó —si es que lo hizo - en la que obtuvo en Estados Unidos. Sin duda lo hizo por vía indirecta, a través de la red de contactos, de recomendaciones, de indicaciones en que se sustenta la actividad editorial, y por medio de la cual se transmiten de un país a otro noticias como la emergencia de un escritor como Bolaño. Barbara Epler, directora de New Directions, la editorial que empezó publicando a Bolaño en Estados Unidos, ha contado de qué forma supo de él. Todo empezó hacia 2003, a través una vehemente recomendación de su amigo el novelista Francisco Goldman. "Al día siguiente le hablé de Bolaño a un amigo editor, quien dijo: 'Ese nombre me suena. Creo haber visto unas galeradas suyas de Harvill, la editorial británica, por la oficina'. Así que le mandé un fax al jefe de Harvill, Christopher MacLehose - un amigo de New Directions - y le pregunté si podíamos hacer una copia de aquellas galeradas. Leí las galeradas de Nocturno de Chile el día que llegaron: me dejaron boquiabierta. Entonces nuestra amiga Susan Sontag proclamó: 'Un maravilloso río de sentimiento, una brillante meditación, una fantasía fascinante; [Nocturno de Chile] es lo más auténtico y singular: una novela contemporánea destinada a tener un lugar permanente en la literatura mundial'. Una recomendación de Sontag como aquella significaba que la crítica literaria seria lo tendría en cuenta"5.

5 Barbara Epler, "Roberto Bolaño en Estados Unidos", texto incluido en Archivo Bolaño 1977-2003, catálogo de la exposición así titulada, producida por el Centro de Cultura Contemporánea de Barcelona (CCCB), comisariada por Juan Insúa y Valerie Miles, e inaugurada el marzo de 2013. El artículo de Epler ocupa las páginas 119-124. 
La misma Barbara Epler puntualiza haberse enterado más tarde de que, antes que ella, Jean Stein y Deborah Treisman, de la revista Grand Street, habían publicado ya algunas cosas de Bolaño en Estados Unidos. Como sea, de las palabras de Epler, no demasiado explícitas, cabe deducir que el "desembarco" de Bolaño en Estados Unidos fue precedido de toda una corriente de recomendaciones directas o indirectas, amistosas o profesionales, que se alimentó no solamente del gusto personal de unos y otros, sino de todo un estado de opinión generado previamente por la entusiasta recepción que Bolaño había obtenido en España, primero, enseguida en diversos países de Latinoamérica (Chile y México en particular, pero también Argentina y otros muchos), y, ya luego, en Francia, en Alemania y en Italia. ¿Hasta qué punto las encendidas palabras de Susan Sontag - siempre atenta a las novedades llegadas de Europa- no participaban de ese estado de opinión?

Ya se ha dicho que, pese a la buena acogida de Nocturno de Chile (By Night in Chile, 2003) y de Estrella distante (Distant Star, 2004), el boom de Bolaño en Estados Unidos no se produjo hasta 2007, cuando tuvo lugar la publicación de Los detectives salvajes (The Savage Detectives), ya no por New Directions sino por Farrar, Straus \& Giroux, una editorial con recursos más que suficientes no sólo para traducir y publicar una obra tan extensa, sino también para apoyarla poniendo en marcha "una impresionante maquinaria de publicidad" (B. Epler). Jonathan Galassi, el presidente de esta prestigiosa editorial, se ha jactado en varias ocasiones de haber contribuido decisivamente al éxito de Roberto Bolaño en Estados Unidos, y de haberlo conseguido gracias a que "esta vez nosotros supimos preparar el momento y educar a la crítica". Interrogado sobre esto último, precisaba: "Educar en un sentido amplio. Crearles expectativas, guiarles. Supimos hacerles descubrir a Bolaño...". Tendría enorme interés acceder a los dossier de prensa y a las acciones promocionales que en su momento hiciera Farrar, Straus \& Giroux, y averiguar con ello si, para "educar" a los críticos estadounidenses, se emplearon textos, materiales, fórmulas extraídas de los comentarios recabados por la obra de Bolaño entre la crítica europea y latinoamericana. Sería una forma de documentar la manera en que se construye, más o menos subrepticiamente, esa "literatura mundial" que Sontag menciona, más allá de los datos acerca del número de idiomas a que un libro ha sido traducido y de su posición en las listas de los libros más vendidos.

Si bien no sigue esta línea de investigación, centrado como está en la recepción de la obra de Bolaño en Estados Unidos (con algún pequeño 
apunte sobre la de Inglaterra), Wilfrido Corral realiza sobre la misma dos observaciones relevantes. La primera, relativa a la importancia que sobre ella ha tenido la labor de dos excelentes traductores: el australiano Chris Andrews (traductor al inglés de Nocturno de Chile, Estrella distante, La literatura nazi en América, Amuleto, La pista de hielo, Monsieur Pain, El gaucho insufrible, El secreto del mal y un par de selecciones de los relatos de Bolaño) y la estadounidense Natasha Wimmer (traductora al inglés de Los detectives salvajes, 2666, Amberes, El Tercer Reich, Entre paréntesis y Los sinsabores del verdadero policía). En el debate sobre la literatura mundial no puede dejarse a un lado el papel determinante que la traducción cumple, no sólo en lo relativo a la calidad de las versiones (sustancial a la hora de transmitir convenientemente, y de alojar en la sensibilidad de los lectores, los valores de un autor), sino también en lo relativo a las políticas que condicionan la decisión de traducir o no a un escritor determinado, y la incidencia que sobre estas políticas tienen factores de todo tipo, no exclusivamente económicos.

La segunda observación de Corral que vale la pena subrayar con la misma insistencia con que él la formula, es la relativa a la incoincidencia entre el orden con que Bolaño publicó sus libros y la secuencia en que éstos fueron apareciendo en inglés. Esta incoincidencia se suele dar bastante a menudo cuando se traduce la obra de un autor cualquiera a otra lengua, y conviene no subestimar las consecuencias que puede tener en su fortuna dentro de esa lengua, tanto en lo relativo a su aceptación como a su comprensión.

La primera de las obras de Bolaño que se tradujo al inglés fue Nocturno de Chile, en diciembre de 2003, medio año después del fallecimiento de Roberto Bolaño. Hemos visto el impacto que la lectura de esta novela produjo en lectoras como Barbara Epler y Susan Sontag. Conforme Epler sospechaba, el libro fue muy bien recibido por "la crítica literaria seria". A su publicación le sucedió - siempre en New Directions - la de Estrella distante, en diciembre de 2004, y la de Amuleto, en enero de 2007, esta última muy pocos meses antes del lanzamiento de Los detectives salvajes, en abril de ese mismo año, ya en Farrar, Straus \& Giroux. Por lo que puede verse, el succès d'estime que obtuvo Bolaño en Estados Unidos le procuró, durante los primeros años, una reputación de escritor de atractivas y extravagantes nouvelles, 
susceptibles de ser tomadas por poemas narrativos. La lectura de estas piezas se realizó sin el conocimiento de sus estrechas imbricaciones con otros textos de Bolaño que los lectores en lengua inglesa iban a tardar aún en conocer. Pues, como es sabido, tanto Estrella distante como Amuleto son desarrollos narrativos de episodios correspondientes a $\mathrm{La}$ literatura nazi en América y a Los detectives salvajes, respectivamente. Por su parte, Nocturno de Chile retoma en un momento dado, estirándolos, fragmentos de una amarga crónica que Bolaño escribiera sobre su retorno a Chile en 1998, después de veinticinco años de ausencia (la crónica se publicó originalmente en la revista Ajoblanco, de Barcelona, en mayo de 1999, bajo el título "El pasillo sin salida aparente", y tuvo para Bolaño amargas secuelas).

La crítica estadounidense - como en su momento la francesaha leído la obra de Bolaño, pues, con las distorsiones que, inevitablemente, le ha impuesto el orden de traducción de sus diferentes títulos. No deben exagerarse las consecuencias de estas distorsiones, pero no cabe tampoco ignorarlas, desentendiéndose del hecho de que la recepción de un autor fuera de su lengua suele aparejar cierto achatamiento de la perspectiva con que esa obra es leída; un achatamiento que se superpone a la precariedad que de por sí conlleva toda lectura de un autor sustraída del contexto que le es más cercano.

El debate sobre la "literatura mundial" adquiere particular acuidad en este punto: el relativo a las simplificaciones, desplazamientos o malentendidos que conlleva una lectura abstraída del marco de referencias en que una obra determinada se explica más cabalmente. Pues no cabe duda de que, aun sin pretenderlo, toda obra ofrece resistencias a su apropiación por parte de un lector desconocedor del marco en que ha sido creada.

Desde este punto de vista, la confrontación entre lo que sobre Bolaño ha dicho la crítica europea y estadounidense y lo que ha dicho la crítica española y latinoamericana resultaría muy esclarecedor. De las observaciones que sobre este asunto hace Wilfrido Corral es posible arrancar una evidencia: fuera del ámbito hispánico, Bolaño ha sido leído con claves a veces muy distintas a las empleadas por los lectores en lengua española.

Por lo que toca a Estados Unidos, me parece significativo que en una de las reseñas de Nocturno de Chile citadas por Corral (la de Kate Levin en el semanario progresista The Nation, en marzo de 2004) se 
diga que se trata de una "novela histórica", y se planteen ciertas objeciones políticas al autor, desde la percepción del libro como una novela que "transmite poderosamente que simplemente no hay cómo ser neutral respecto a regímenes como el de Pinochet" (cito a través de Corral). Me parece elocuente, por otro lado, que James Wood, el prestigioso crítico de The New Yorker a quien Corral atribuye un papel determinante en la buena acogida de Bolaño en el ámbito anglosajón, tenga a Nocturno de Chile como la mejor obra del escritor. Y no sólo eso: en una entrevista con Gabriel Pasquini (publicada en Letras Libres en septiembre de 2009), al ser preguntado acerca de Roberto Bolaño, Wood responde: "Mi impresión es que es más fuerte en sus nouvelles, como Nocturno de Chile". Una opinión que según Corral está bastante extendida, al parecer, entre la crítica anglosajona.

Alguna vez habrá que reflexionar en serio sobre la importancia que tiene la puerta de acceso a un escritor, tanto en un plano particular como colectivo. Quizá en ello resida una de las diferencias sustanciales en la forma en que un autor es leído fuera de su país. En cualquier caso, del abundante acopio de citas que Corral hace de las reseñas que han recibido en Inglaterra y Estados Unidos los libros de Roberto Bolaño, me atrevo a extraer una conclusión provisional (pendiente de ser contrastada por la lectura cabal de esas mismas reseñas): la mayor parte de ellas abundan en lugares comunes, cuando no incurren en malentendidos o en errores de bulto, y en general entrañan una comprensión ligeramente desplazada, sí, pero no más amplia ni mejor, al menos en términos generales, de la que esos mismos libros han tenido en lengua española.

Insisto en lo revelador que sería establecer una amplia comparativa entre los discursos críticos de una y otra lengua, poniendo de manifiesto qué elementos comparten uno y otro, qué aspectos enfatizan u obvian, y por qué. De este modo quizá cabría detectar, por ejemplo, cierta tendencia de la crítica estadounidense a politizar la lectura de las obras de Bolaño, tendencia justificada sin duda por el hecho de que las dos primeras novelas que allí se publicaron de este autor, Nocturno de Chile y Estrella distante, sean novelas que remiten muy explícitamente a Chile y a la dictadura de Pinochet.

Por razones parecidas, en las críticas estadounidense sobre los libros de Bolaño se detecta una pronunciada tendencia a subrayar su con- 
dición de chileno y de latinoamericano, con todos los tópicos que ello comporta, a costa de rebajar esa condición de escritor extraterritorial sobre la que me cupo llamar la atención hace ya varios años, invocando una categoría puesta en circulación mucho antes por George Steiner (categoría, dicho sea de paso, que me sigue pareciendo especialmente fértil en relación a Bolaño, y que sería oportuno confrontar con las categorías "mundial", "global" o "internacional").

$*$

A propósito de esto último, no está de más recordar que entre los logros de Bolaño se cuenta el de haber contribuido a cambiar el paradigma de escritor latinoamericano vigente hasta hace relativamente poco. Este paradigma estaba conformado por los escritores del gran boom de la narrativa latinoamericana de los años sesenta. La inmensa mayoría de los que se dieron a conocer después y que alcanzaron, como aquéllos, una cierta repercusión internacional, fueron asimilados a ese paradigma. Y así siguió ocurriendo hasta la irrupción de Bolaño, cuya

${ }^{6}$ Ignacio Echevarría, "Bolaño extraterritorial", texto de la charla de apertura de un seminario que dio Roberto Bolaño sobre su obra en el marco de un ciclo organizado en Barcelona por el Instituto Catalán de Cooperación Iberoamericana (ICCI), en noviembre de 2002. El texto ha quedado recogido en Ignacio Echevarría, Desvios. Un recorrido crítico por la reciente narrativa latinoamericana, 2006, pp. 44-53, y en Bolaño salvaje, 2008, pp. 431-554. "El artista y el escritor - escribía George Steiner en 1971 - son turistas infatigables que miran los escaparates en los que se exhibe toda la gama de las formas existentes. Las condiciones de estabilidad lingüística, de conciencia local y nacional en que floreció la literatura desde el Renacimiento hasta, digamos, la década de los 50, se encuentran actualmente bajo enorme presión. Faulkner y Dylan Thomas posiblemente serán considerados algún día como los últimos escritores 'con casa' de la literatura mundial". Steiner atribuía a la condición de exiliados que comparten tantos escritores contemporáneos "el principal impulso de la literatura actual", ocupándose de precisar que dicha condición no tiene por qué obedecer siempre a motivaciones políticas, sino que tiene que ver con algo más amplio: "con el problema más general de la pérdida de centro". Aunque Steiner apenas la bosquejaba, y lo hacía con bastante imprecisión, esta categoría - la de extraterritorial - ha ganado entretanto connotaciones que la hacen cada vez más útil. Sin necesidad de circunscribirla al ámbito estrictamente idiomático, lo cierto es que en el contexto del nuevo "internacionalismo cultural", bajo los efectos "globalizadores" de la cultura de masas, la noción de extraterritorialidad subvierte mejor aún que la de "literatura mundial"- la ya anticuada y más complaciente de cosmopolitismo, para sugerir aquellos aspectos de la literatura moderna en que ésta se perfila, en palabras del propio Steiner, como "una estrategia de exilio permanente" (George Steiner, Extraterritorial. Ensayos sobre literatura y la revolución lingüística [1971], 2002). 
narrativa redefine la condición misma de escritor latinoamericano, y socava muchos de los presupuestos asociados a ella, erosionando la situación que - en un pasaje ya célebre, y profusamente citado, muy en particular en los debates sobre "literatura mundial"— Juan José Saer acertó a describir en los siguientes términos: "La tendencia de la crítica europea a considerar la literatura latinoamericana por lo que tiene de específicamente latinoamericano me parece una confusión y un peligro, porque parte de ideas preconcebidas sobre América Latina y contribuye a confinar a los escritores en el ghetto de la latinoamericanidad. Si la obra de un escritor no coincide con la imagen latinoamericana que tiene un lector europeo se deduce inmediatamente de esta divergencia la inautenticidad del escritor, descubriéndosele además, en ciertos casos, singulares inclinaciones europeizantes. Lo que significa que Europa se reserva los temas y las formas que considera de su pertenencia dejándonos lo que concibe como típico de América Latina" ("La selva espesa de lo real", en Una literatura sin atributos, Santa Fe, Universidad Nacional del Litoral, 1988).

Lo que Saer dice sobre la crítica europea admite ser traspolado, con tantos o más motivos, a la crítica estadounidense y, más ampliamente, proyectado a los mecanismos de recepción y de construcción de lo que se quiera entender por "literatura mundial". Las "ideas preconcebidas sobre América Latina" que Saer menciona no han dejado de operar en la recepción de la obra de Bolaño, pero ésta, sin embargo ha conseguido remover algunas de ellas, a fuerza de entretejerlas a un conjunto de ideas más amplio y más complejo, también más perturbador. "Latinoamérica es como el manicomio de Europa", declaraba Bolaño en 2002 a un entrevistador francés. "Tal vez, originalmente, se pensó en Latinoamérica como el hospital de Europa, o como el granero de Europa. Pero ahora es el manicomio. Un manicomio salvaje, empobrecido, violento, en donde, pese al caos y a la corrupción, si uno abre bien los ojos, es posible ver la sombra del Louvre"7.

Por otra parte, a la hora de explicarse la fortuna de Bolaño en Estados Unidos conviene reparar en un aspecto nunca suficientemente

${ }^{7}$ Declaración hecha por Roberto Bolaño durante la entrevista de Dominique Aussenac publicada en la revista Le Matricule septiembre de 2002; el pasaje está recogido en su Bolaño por sí mismo, Andrés Braithwaite (ed.), 2006, pp. 269-280; el pasaje citado se encuentra en la p. 269. 
destacado: el parentesco que la literatura de Bolaño guarda con la de aquella nación. El éxito en Estados Unidos de novelas como Los detectives salvajes y 2666 no puede desvincularse de la familiaridad de sus patrones compositivos con los de la gran narrativa estadounidense. El mismo Bolaño dejó dicho, a propósito de Los detectives salvajes, que podía reconocerse en esta novela "una lectura, una más de las tantas que se han hecho en la estela del Huckleberry Finn de Mark Twain". Y añadía: "el Mississippi de Los detectives es el flujo de voces de la segunda parte de la novela". Por su parte, la crítica no ha cesado de establecer paralelismos entre 2666 y Moby Dick, de Herman Melville.

Con ocasión de escribir un prólogo para Las aventuras de Huckleberry Finn, en 1999, Bolaño dijo: "Todos los novelistas americanos, incluidos los autores de lengua española, en algún momento de su vida consiguen vislumbrar dos libros recortados en el horizonte, que son dos caminos, dos estructuras y sobre todo dos argumentos. En ocasiones, dos destinos. Uno es Moby Dick, de Melville, el otro es Las aventuras de Huckleberry Finn, de Mark Twain"".

Pues bien: Bolaño recorrió los dos caminos, exploró las dos estructuras, cultivó los dos argumentos. Y asumió los dos destinos, también. No debe subestimarse el papel que ello ha tenido en la empatía con que su literatura ha sido acogida por los lectores estadounidenses. La hermandad que Bolaño sugiere al hablar de "los novelistas americanos" no es retórica. Tiene importancia, aquí, recordar el título del libro con el que por primera vez alcanzó una notoria visibilidad: La literatura nazi en América. En cierta ocasión, un entrevistador mencionó este título equivocadamente: La literatura nazi en Latinoamérica, dijo. A lo que Bolaño puntualizó: “...en América: es todo el continente. Hay varios autores norteamericanos. Te lo aseguro" ". A Susan Sontag, buena lectora, no se le escapó la importancia de este dato. Barbara Epler cuenta que fue ella quien le recomendó que la versión inglesa de la novela

${ }^{8}$ Roberto Bolaño, "Nuestro guía en el desfiladero", prólogo a la edición de Las aventuras de Huckleberry Finn, de Mark Twain, publicada en la Biblioteca Universal del Círculo de Lectores, Barcelona, 1999; recogido en Entre paréntesis. Ensayos, artículos y discursos (1998-2003), 2013, 241-245; véanse también las pp. 13 y 353.

${ }^{9}$ Entrevista de Eliseo Álvarez publicada en la revista Turia, Barcelona, junio de 2005; recogida en Bolaño por sí mismo, edición de Andrés Braithwaite, 2006, pp. 34-45. 
llevara por título Nazi Literature in the Americas, con empleo del plural, para evitar reduccionismos. "¡Cuídate de llamarlo Nazi Literature in America!", le había advertido.

Habría que intentar levantar — si no se ha intentado ya- un mapa de las devociones literarias de Bolaño. Se trata de una tarea difícil, dada la frondosidad de sus lecturas. En lo que toca a la literatura estadounidense, ese mapa haría notorio el ascendente que sobre Bolaño tuvieron escritores como Twain y Melville, por supuesto, pero también William Burroughs y los escritores de la generación beat; toda la novela negra, hasta llegar a James Ellroy; Philip K. Dick y los autores de ciencia ficción; Carver y la gran tradición de los cuentistas norteamericanos... Por nombrar ahora modelos a los que el mismo Bolaño se refirió con admiración en uno u otro lugar. A ellos habría que sumar muchos otros autores que sin duda leyó y admiró, y con los que su obra revela evidentes conexiones, como puede ser el Kurt Vonnegut de Matadero cinco o el John Cheever de La crónica de los Wapshop y de Bullet Park, entre muchos otros. Por no entrar aquí en el territorio de la poesía.

Más complicado sería el levantamiento de ese mapa en lo relativo a las lecturas de escritores europeos, tanto ingleses como continentales, incluida la literatura española. Las lecturas de Bolaño alcanzaban parajes muy remotos, tanto en el tiempo como en el espacio. En cuanto a libros y escritores latinoamericanos, Bolaño sembró muchas pistas, que en algunos casos velaban otras igualmente relevantes. Así, por ejemplo, el magisterio insistentemente invocado de Borges y Cortázar oscurece el que ejercieron sobre él Rulfo y Onetti. Y luego, ya en otro plano, está la red de complicidades que estableció con algunos escritores latinoamericanos de su misma franja generacional, y mediante la cual Bolaño contribuyó a actualizar el canon contemporáneo de la narrativa del continente, en el que hoy día figuran nombres como los de Daniel Sada, Juan Villoro, Horacio Castellanos Moya, Rodrigo Rey Rosa, Ricardo Piglia, César Aira, Alan Pauls, Rodrigo Fresán o Pedro Lemebel, entre otros, todos ellos reivindicados por él en una u otra ocasión.

A la hora de postular su nombre como representante de la nueva "literatura mundial" — cualquiera cosa que se quiera entender por 
ello-, el escrutinio de la biblioteca de Bolaño quizás arrojase tanta o más luz que el recuento y análisis de las reseñas dedicadas a sus libros. $\mathrm{Su}$ voracidad lectora, su nomadismo tanto biográfico como literario, su asimilación y combinación de modelos procedentes de una y otra orilla del Atlántico, el modo en que su propia literatura navega entre esas dos orillas en un constante recorrido de ida y vuelta, son elementos todos ellos que sirven para explicar la aceptación y el aplauso prácticamente unánime que Bolaño ha cosechado en buena parte del mundo, donde lectores de todo tipo detectan en su obra resonancias que les son familiares.

Pero más arriba he aludido muy pasajeramente a las circunstancias extraliterarias invocadas por algunos para explicar el fenómeno creado en torno a Bolaño, muy en particular en Estados Unidos. Me refiero a circunstancias extraliterarias, como la de su muerte relativamente temprana, cuyo nimbo trágico intensifica la leyenda de una juventud borrascosa. Por mucho que no sirvan por sí solas para justificar - como se ha pretendido en más de una ocasión - la sensacional fortuna de la obra de Bolaño, conviene no desdeñar la forma en que estas circunstancias potencian algunos temas tan cardinales dentro de esa obra como son el tema del fracaso de la revolución y de la vanguardia, el tema recurrente de los escritores perdidos, o el de la risible posteridad.

Bolaño manifestó en muchas ocasiones su escepticismo respecto a cualquier idea de posteridad. A veces, con un extraño pathos, como en este pasaje de un correo electrónico dirigido a Rodrigo Fresán: "Entiendo que haya quienes creen en la inmortalidad del alma, incluso puedo entender a los que creen en el Paraíso y el Infierno y en esa estación intermedia y sobrecogedora que es el Purgatorio, pero cuando escucho a un escritor hablar de la inmortalidad de determinadas obras literarias me dan ganas de abofetearlo. No estoy hablando de pegarle sino de darle una sola bofetada y después, probablemente, abrazarlo y confortarlo" 10 .

${ }^{10}$ Pasaje citado por Rodrigo Fresán en "Apuntes para un atlas del planeta de los monstruos", prólogo a una edición en un único volumen de Estrella distante, Amuleto y Nocturno de Chile, en Roberto Bolaño, Tres novelas, 2003, p. 19 n. 
En 2666, en "La parte de Archimboldi", se cuenta cómo el editor Bubis y sus colaboradores se burlan de los escritores que se revelan "dispuestos a usurpar cualquier reputación, con la certeza de que esto les proporcionaría una posteridad, cualquier posteridad". La sola idea provoca "la risa de las correctoras y de los demás empleados de la editorial e incluso la sonrisa resignada de Bubis, pues nadie mejor que ellos sabía que la posteridad era un chiste de vodevil que sólo escuchaban los que estaban sentados en primera fila".

¿Pensaría Bolaño que era él uno de los que estaban sentados en primera fila? Razones no le faltaban. Como sea, en otra de las entrevistas que concedió asegura que "aspirar a la posteridad es el mayor absurdo imaginable, son trabajos de amor perdidos, como diría Shakespeare". Para añadir a continuación: "Pero precisamente por esto tiene también su lado hermoso...".

$\mathrm{Al}$ tema de la posteridad va asociado el del escritor perdido, que vertebra sus dos novelas mayores, sin duda, pero que emerge a lo largo de toda su obra, asomándola una y otra vez al abismo a cuyo borde mismo transcurrió buena parte de la trayectoria de Bolaño como escritor: el abismo de olvido en que se sumen las obras desconocidas, los escritores ignorados.

De Los detectives salvajes se dice en el propio libro que es "una historia de poetas perdidos y de revistas perdidas y de obras sobre cuya existencia nadie conocía una palabra”. En cuanto a 2666, entre las notas preparatorias de la novela hay una en la que se apunta la siguiente explicación para la voz que, en "La parte de Amalfitano", este personaje oye cuando está solo, y con la que dialoga: "Pregunta Amalfitano a la voz el porqué de su viaje a través del tiempo. La voz le responde que viaja a rescatar obras. Obras perdidas. ¿Por qué? Porque, por ejemplo, las obras perdidas, en literatura, suelen ser tan buenas ( 0 mejores!) que las que se imprimieron y perdurarán"...

Habría mucho que decir sobre el tema de los escritores perdidos y de las obras perdidas en Bolaño, íntimamente vinculado, a su vez, al de la posteridad, y uno y otro relacionados, en definitiva, con el tema de la muerte, que es en realidad el tema de fondo que recorre la obra entera de Bolaño, quien se refirió en cierta ocasión al "silencio de la muerte" como aquel "que corta de tajo lo que pudo ser y nunca más va a poder ser, lo que no sabremos jamás" 11 .

${ }^{11}$ Declaración hecha por Roberto Bolaño durante la entrevista de Eliseo Álvarez publicada en la revista Turia, Barcelona, junio de 2005; recogida en Bolaño por sí mismo, edición de Andrés Braithwaite, 2006. 
No cabe duda de que la muerte de Bolaño, apenas cumplidos los cincuenta años de edad, y cuando estaba a punto de concluir un libro de las proporciones gigantescas de 2666 , escrito en feroz competencia con el tiempo, amplifica poderosamente el peso que la muerte misma tiene en su obra, y contribuye a dotar a ésta de una dimensión heroica. Lo hace, además, en unos tiempos en que el acelerado encogimiento de todo horizonte de posteridad mueve a muchos a plantearse la condición trágica del arte y del artista, y a sondear — como se está haciendo aquí mismo - la contingencia de los mecanismos que determinan el éxito y la canonización de un autor, y su eventual consagración como clásico.

$*$

En cuanto al tema del fracaso de la revolución y de la vanguardia, quizá contengan, más que ningún otro, la clave de la atención que la obra de Bolaño ha conquistado por doquier, y una espinosa justificación del lugar tan destacado que su figura ha terminado por ocupar en la "literatura mundial".

En 2009, en el número de verano de la revista Comparative Literature, Sarah Pollack, profesora de la City University of New York, publicó un ensayo titulado "Latin America Translated (Again): Roberto Bolaño's The Savage Detectives in the United States". El ensayo discurre sobre la construcción del mito de Bolaño en Estados Unidos, que según ella fue cuidadosamente planeada (hipótesis que parecen refrendar las palabras de Jonathan Galassi citadas más arriba). El énfasis que la mayoría de los artículos publicados por la prensa estadounidense sobre Bolaño pusieron en los bien conocidos episodios de su juventud tumultuosa abonaban, según Pollack, la construcción de ese mito. "Estos episodios iconoclastas eran demasiado tentadores como para que no fueran convertidos en una tragedia de proporciones míticas: he aquí alguien que vivió los ideales de su juventud hasta sus últimas consecuencias. $\mathrm{O}$ como rezaba el titular de uno de esos artículos: ¡Descubran al Kurt Kobain de la literatura latinoamericana!".

Para Pollack, el mito propicia una lectura de Los detectives salvajes en clave conservadora, dado que, si bien refuerza la idea de que la novela es, en buena medida, un canto a la juventud y a la aventura, subraya que ese canto es elevado en clave elegíaca, dando a entender así que la rebeldía es una actitud pasajera, condenada a someterse al princi- 
pio de realidad. Pollack advierte de la tendencia (según ella inducida) a leer Los detectives salvajes como un cuento moral, en el sentido de que “está muy bien ser un rebelde descarado a los diecisiete años, pero si uno no crece y no se convierte en una persona adulta, seria y asentada, las consecuencias pueden ser trágicas y patéticas". Y añade: "Es como si Bolaño estuviera confirmando lo que las normas culturales de Estados Unidos promocionan como la verdad".

Comentando el ensayo de Pollack, Horacio Castellanos Moya (de quien tomo tanto la noticia del ensayo en cuestión como la traducción de las citas empleadas) se lamenta de que "algunos lectores estadounidenses, a través de Los detectives salvajes, quieran confirmar sus peores prejuicios paternalistas hacia Latinoamérica", entre los que se cuentan "la superioridad de la ética protestante del trabajo o esa dicotomía por la cual los norteamericanos se ven a sí mismos como trabajadores, maduros, responsables y honestos, mientras que a los vecinos del sur nos ven como haraganes, adolescentes, temerarios y delincuentes" 12 .

El mismo Horacio Castellanos Moya observa que la propia biografía de Bolaño potencia una lectura de este tipo, dado que él mismo "necesitó asentarse y contar con una sólida base familiar para escribir la imponente obra que escribió". Pero no sólo su biografía: también muchas declaraciones de Bolaño dan pie a tendenciosas interpretaciones en el sentido apuntado por Pollack. Así, por ejemplo, en el texto que redactó para ser incluido en el programa de mano del acto en que recogió el Premio Rómulo Gallegos de 1999, Bolaño decía de Los detectives salvajes que intenta "reflejar una cierta derrota generacional y también la felicidad de una generación, felicidad que en ocasiones fue el valor y los límites del valor"13.

Al discurso que leyó en esa misma ocasión, el llamado "Discurso de Caracas", pertenece el célebre pasaje en el que, después de evocar un conocido capítulo del Quijote, dice Bolaño: "Y esto me viene a la cabeza porque en gran medida todo lo que he escrito es una carta de amor o de despedida a mi propia generación, los que nacimos en la década

${ }^{12}$ Horacio Castellanos Moya, "El mito de Bolaño en Estados Unidos", artículo publicado originalmente en el suplemento ADN del diario La Nación, de Buenos Aires, el 19 de septiembre de 2009; recogido en La metamorfosis del sabueso. Ensayos personales y otros textos, 2011, pp. 118-123.

${ }^{13}$ R. Bolaño, "Acerca de Los detectives salvajes" [1999], recogido en su Entre paréntesis, Ignacio Echevarría, editor, 2013, pp. 326-327. 
del cincuenta y los que escogimos en un momento dado el ejercicio de la milicia, en este caso sería más correcto decir la militancia, y entregamos lo poco que teníamos, lo mucho que teníamos, que era nuestra juventud, a una causa que creímos la más generosa de las causas del mundo y que en cierta forma lo era, pero que en la realidad no lo era". Palabras a las que añade, inmediatamente a continuación: "De más está decir que luchamos a brazo partido, pero tuvimos jefes corruptos, líderes cobardes, un aparato de propaganda que era peor que una leprosería, luchamos por partidos que de haber vencido nos habrían enviado de inmediato a un campo de trabajos forzados, luchamos y pusimos toda nuestra generosidad en un ideal que hacía más de cincuenta años que estaba muerto, y algunos lo sabíamos, y cómo no lo íbamos a saber si habíamos leído a Trotski o éramos trotskistas, pero igual lo hicimos, porque fuimos estúpidos y generosos, como son los jóvenes, que todo lo entregan y no piden nada a cambio, y ahora de esos jóvenes ya no queda nada, los que no murieron en Bolivia murieron en Argentina o en Perú, y los que sobrevivieron se fueron a morir a Chile o a México, y a los que no mataron allí los mataron después en Nicaragua, en Colombia, en El Salvador. Toda Latinoamérica está sembrada con los huesos de estos jóvenes olvidados" 14 .

En otros muchos lugares, especialmente en entrevistas, Bolaño evocó con tintes elegíacos el sueño revolucionario de su juventud, compartido por buena parte de los miembros de su generación. Él mismo se consideraba un "superviviente" ("lo digo así porque muchos de mis amigos han muerto, sea en las luchas revolucionarias armadas o por sobredosis de drogas o por el sida" ${ }^{15}$, una condición de la que es fácil hacer derivar un mensaje como el que Sarah Pollack sostiene que instila subrepticiamente la construcción de su mito.

Pero no se trata solamente de la derrota de los ideales revolucionarios, de su fracaso presentado $-\mathrm{y}$ asumido, en cierta medida-

${ }^{14}$ R. Bolaño, "Discurso de Caracas" [1999], recogido en su Entre paréntesis, Ignacio Echevarría, editor, pp. 31-39.

15 Declaración hecha por Roberto Bolaño durante la entrevista de Héctor Soto y Matías Bravo publicada en la revista Capital, Santiago, diciembre de 1999; recogida en Bolaño por sí mismo, edición de Andrés Braithwaite, 2006, pp. 49-53. 
como inevitable. Se trata también de la derrota de otra utopía: la de la vanguardia artística, tantas veces solidaria de la revolución. Preguntado acerca de cómo los personajes que pueblan Los detectives salvajes están "cruzados por la idea de revolucionar el arte y cambiar el mundo", respondía Bolaño: "Revolucionar el arte y cambiar la vida eran los objetivos del proyecto de Rimbaud. Y reinventar el amor. En el fondo, hacer de la vida una obra de arte"16. $\mathrm{Y}$ en otra ocasión dijo: "Pero mi interés básico era ése, vivir como poeta. Para mí, ser poeta era, al mismo tiempo, ser revolucionario y estar totalmente abierto a cualquier manifestación cultural, a cualquier expresión sexual, en fin, abierto a todo"17.

El proyecto revolucionario, pues, era inseparable, para Bolaño, del proyecto artístico. Y el fracaso de uno conlleva el del otro. De ahí que las suspicacias de Sarah Pollack respecto a la tendenciosa lectura política que estimula la particular mitificación de Bolaño deban hacerse extensibles a determinadas prácticas artísticas que el canon cultural sólo ha tolerado al precio de museizarlas y fosilizarlas.

En la obra de Bolaño, la cuestión de las vanguardias, de su vigencia y de su obsolescencia, ocupa un lugar sin duda central, como queda de manifiesto en su poesía y ya en sus primeras novelas ( $L a$ literatura nazi en América, Estrella distante $)^{18}$. Se trata de una cuestión ligada a su propia experiencia de la juventud y de los ideales que entonces sostuvo. Como en el caso de la revolución, no es fácil llegar a conclusiones firmes sobre las posiciones de Bolaño a este respecto, a veces recalcitrantes y otras veces melancólicas. No hay que confundir sus propias opiniones con el dibujo que en su obra hace de la derrota y el desleimiento de la vanguardia y de sus eventuales conquistas. Sus declaraciones, llenas de humor y de ambigüedades, tampoco contribuyen gran cosa a esclarecer sus verdaderas ideas al respecto, razón por la cual conviene ser muy prudente en este terreno.

${ }^{16}$ Ibídem.

${ }^{17}$ Declaración hecha por Roberto Bolaño durante la entrevista de Eliseo Álvarez publicada en la revista Turia, Barcelona, junio de 2005; recogida en su Bolaño por sí mismo, edición de Andrés Braithwaite, 2006.

${ }_{18}$ Mientras redacto este artículo, llega a mis manos la tesis doctoral que está a punto de presentar David Guzmán en la Universidad de Deusto, Facultad de Ciencias Sociales, bajo el título "Detectives en la vanguardia: Modernidad y posmodernidad en Bolaño”, donde se hace un lúcido planteamiento del tema de la vanguardia en su obra. 
En otro lugar me he referido a las implicaciones que, desde el punto de vista de su temprana adscripción a la vanguardia, tiene el paso de Bolaño desde la poesía a la novela. A este respecto, Alejandro Zambra ha subrayado con acierto cómo, en el caso de Bolaño, el narrador hace comprensible al poeta. Cómo el novelista inteligible pone en escena al poeta ininteligible. Zambra sugiere que la novelística de Bolaño viene a ser la traducción de su poesía. Sugiere más: sugiere que el tránsito de la poesía a la novela, por parte de Bolaño, se produce al precio de una renuncia, alentada precisamente por esa conciencia no sólo de incomunicabilidad, sino también de imposibilidad de la poesía. "La obra de Bolaño cuenta la historia de un poeta resignado a novelista", afirma Zambra ${ }^{19}$.

La condición de superviviente que Bolaño reclamaba para sí no sólo remite, así, a los pactos que él mismo hubo de hacer con una forma de vida relativamente "aburguesada", o cuando menos desentendida en alto grado del arrebato de sus años juveniles. Es una condición que atañe a su faceta de poeta tramutado en novelista.

Se ha observado a menudo que el género de la nueva "literatura mundial" es la novela. Una observación a cuya luz cobra sentido preguntarse si la entronización de Bolaño en el marco de esa "literatura mundial" no estaría relacionada, siquiera sea subliminalmente, con esa indirecta tematización que él hace, a través de sus novelas, de la victoria del "género burgués" por excelencia sobre la poesía.

He sostenido alguna vez que el lugar de Bolaño en el canon es un agujero ${ }^{20}$. No me refería con ello al vacío dejado por su muerte, o no solamente. A propósito de Los detectives salvajes, observaba Alan Pauls que, siendo una novela que habla todo el rato de poetas, en ella sin embargo la poesía queda fuera. Poco antes que Pauls, en la misma línea, el poeta mexicano Luis Felipe Fabre ya había observado, también a propósito de Los detectives salvajes, que sus protagonistas "son lectores de huecos". Poetas ellos mismos, viven esta condición que los caracteriza — la de poetas - en clave elegíaca, añorando o buscando empedernida-

19 Alejandro Zambra, "La poesía de Roberto Bolaño", recogido en su No leer. Crónicas y ensayos sobre literatura, selección y edición de Andrés Braithwaite, 2010.

${ }^{20}$ Lo hice en una charla impartida en la Georgetown University de Washington, en el transcurso de unas jornadas de homenaje a Roberto Bolaño organizadas en noviembre de 2008. 
mente el rastro perdido de la poesía entendida nada menos que "como una tentativa de transformación del mundo".

Los detectives salvajes, sigue diciendo Luis Felipe Fabre, viene a ser una asamblea de ausencias, de poetas ignorados. Se trata, en definitiva, de "un libro que describe la silueta de una ausencia". Y esa ausencia no sería otra que "la del poema imposible"21.

¿Imposible? ¿Desde cuándo?

Quizá desde siempre. Si bien lo decisivo, en este punto, es creer o no en esa imposibilidad.

La obra de Roberto Bolaño se edifica desde el convencimiento de esa imposibilidad. Pero también desde la nostalgia, desde la terrible nostalgia de un tiempo en que esa imposibilidad no había sido aún asumida. La gran operación de Bolaño consiste en tematizar el fin de la revolución y de la vanguardia, y de hacerlo a fuerza de remitir una y otra a un estrato legendario.

La "solución Bolaño", según Alan Pauls: "inventar la Vanguardia como leyenda y convertirse en su mitógrafo, su mitólatra, su mitócrata"22. Dicho en otras palabras: hacer sentir, en el seno del fatalismo que caracteriza la cultura contemporánea, el hueco dejado en su centro mismo por la utopía. Desde este punto de vista, cabe entender la obra entera de Bolaño como el negativo de la pasión utópica. Otra cosa es que de ello se pretenda sacar una lección conservadora que el mismo Bolaño sin duda hubiera impugnado, persuadido como estaba de que el valor de la literatura consistía en sostener vivo el espíritu de la utopía, aun sabiéndola condenada a su incumplimiento.

A propósito de la multitud de poetas que pueblan la obra de Bolaño, Luis Felipe Fabre observa agudamente que, lejos de alentar ningún optimismo sobre el futuro de la poesía misma, son para Bolaño "la señal de una catástrofe: la del fin de la poesía como una tentativa de transformación del mundo".

${ }^{21}$ Luis Felipe Fabre, "La poesía está en otra parte: tras la pista de Los detectives salvajes", recogido en su Leyendo agujeros. Ensayos sobre (des)escritura, antiescritura y no escritura, 2005, pp. 68-82.

${ }^{22}$ Alan Pauls, "La solución Bolaño", texto leído el 8 de abril de 2006 en el Encuentro Internacional sobre Roberto Bolaño realizado en la UNAM (Universidad Nacional Autónoma de México); recogido en su Temas lentos, selección y edición de Leila Guerrero, 2012, pp. 60-69. 
Es en el hueco dejado por la poesía así entendida donde Bolaño levanta su obra novelística. A través de ella, los lectores del presente se asoman a ese hueco y experimentan la emoción del abismo. La mayoría aplauden aliviados y satisfechos de no haber sucumbido a su atracción. Pero Bolaño no les habla desde fuera, sino desde el interior mismo de ese hueco.

\section{REFERENCIAS}

Álvarez, Eliseo. Entrevista a Roberto Bolaño. Revista Turia, junio de 2005. [Recogida en Roberto Bolaño; Andrés Braithwaite (editor), Bolaño por sí mismo: Entrevistas escogidas. Santiago de Chile: Ediciones Universidad Diego Portales, 2006].

Aussenac, Dominique. Entrevista a Roberto Bolaño. Revista Le Matricule Des Anges, Montpellier, septiembre de 2002.

Bolaño, Roberto. Estrella distante. Anagrama, 1996. [Distant Star. New Directions, 2004].

- Los detectives salvajes. Anagrama, 1998. [The Savage Detectives. Farrar, Straus \& Giroux, 2007].

"El pasillo sin salida aparente". Revista Ajoblanco, mayo 1999, Barcelona.

- Amuleto. Anagrama, 1999. [Amulet. New Directions, 2006].

"Nuestro guía en el desfiladero". Prólogo a la edición de Las aventuras de Huckleberry Finn, de Mark Twain. Barcelona: Biblioteca Universal del Círculo de Lectores, 1999. [Recogido en Roberto Bolaño, Entre paréntesis. Ensayos, artículos y discursos (1998-2003). Ignacio Echevarría (editor). Anagrama, 2013].

- Nocturno de Chile. Anagrama, 2000. [By Night in Chile. New Directions, 2003].

- Tres novelas. Barcelona: Círculo de Lectores, 2003.

2666. Anagrama, 2004.

Andrés Braithwaite (editor). Bolaño por sí mismo: Entrevistas escogidas. Santiago de Chile: Ediciones Universidad Diego Portales, 2006.

- Ignacio Echevarría (editor). Entre paréntesis. Ensayos, artículos y discursos (1998-2003). Anagrama, 2013.

- "Acerca de Los detectives salvajes" [1999]. En Roberto Bolaño; Ignacio Echevarría (editor), Entre paréntesis. Ensayos, artículos y discursos (1998-2003). Anagrama, 2013.

"Discurso de Caracas" [1999]. En Roberto Bolaño; Ignacio Echevarría (editor). Entre paréntesis. Ensayos, artículos y discursos (1998-2003). Anagrama, 2013. 
Casanova, Pascale. La République mondiale des lettres. Paris: Seuil, 1999. [Trad. española de Jaime Zulaika, La república mundial de las letras. Barcelona: Anagrama, 2001].

Castellanos Moya, Horacio. "El mito de Bolaño en Estados Unidos". Suplemento ADN del diario La Nación de Buenos Aires, el 19 de septiembre de 2009. [Recogido en Horacio Castellanos Moya, La metamorfosis del sabueso. Ensayos personales y otros textos. Santiago de Chile: Ediciones Universidad Diego Portales, 2011].

Corral, Wilfrido H. Bolaño traducido: Nueva literatura mundial. Madrid: Ediciones Escalera, 2011.

Damrosch, David (editor). Teaching World Literature. Pearson Education Inc. 2003.

Echevarría, Ignacio. "Bolaño extraterritorial” [noviembre 2002]. En Ignacio Echevarría, Desvíos. Un recorrido crítico por la reciente narrativa latinoamericana. Santiago de Chile: Ediciones Universidad Diego Portales, 2006, pp. 44-53. [Recogido también en Edmundo Paz Soldán y Gustavo Faverón Patriau (eds.), Bolaño salvaje. Barcelona: Candaya, 2008].

- Charla en jornada "Roberto Bolaño: Homage to the Savage", organizada por Georgetown University (School of Foreign Service), 21 de noviembre de 2008.

Epler, Barbara. "Roberto Bolaño en Estados Unidos". En Archivo Bolaño 1977-2003, catálogo de la exposición "Roberto Bolaño en Estados Unidos". Centro de Cultura Contemporánea de Barcelona (CCCB), marzo de 2013.

Fabre, Luis Felipe. "La poesía está en otra parte: Tras la pista de Los detectives salvajes". En Luis Felipe Fabre, Leyendo agujeros. Ensayos sobre (des) escritura, antiescritura y no escritura. México: Conaculta, 2005.

Fresán, Rodrigo. "Apuntes para un atlas del planeta de los monstruos", Prólogo. En Roberto Bolaño, Tres novelas. Barcelona: Círculo de Lectores, 2003, p. 19n.

Furió, Vicenç. Arte y representación. Estudios sobre el reconocimiento artístico. Edicions Universitat Barcelona, 2012.

"Valores relativos, pero no arbitrarios". Culturas (suplemento cultural del diario La Vanguardia, Barcelona), $\mathrm{N}^{\circ}$ 564, abril de 2013, pp. 3-4.

Gramuglio, María Teresa. "El retorno de la literatura mundial". Diario de Poesía, N 81, diciembre de 2010-abril de 2011, Buenos Aires-Rosario.

Guzmán, David. "Detectives en la vanguardia. Modernidad y posmodernidad en Bolaño". Proyecto de tesis doctoral, Universidad de Deusto, Facultad de Ciencias Sociales, 2013.

Jösch, Melanie. Entrevista con Roberto Bolaño. Diario La Tercera, Santiago de Chile, 25 de febrero de 2000.

Levin, Kate. Reseña de Nocturno de Chile. Revista The Nation, March 2004.

Ossandón, Felipe. Entrevista a Roberto Bolaño. Diario El Mercurio, Santiago de Chile, 14 de febrero de 2003. 
Pauls, Alan. "La solución Bolaño" [8 de abril de 2006]. En Alan Pauls, Temas lentos. Leila Guerrero, selección y edición. Santiago de Chile: Ediciones Universidad Diego Portales, 2012.

Pollack, Sarah. "Latin America Translated (Again): Roberto Bolaño's The Savage Detectives in the United States". Comparative Literature, Summer 2009.

Saer, Juan José. “La selva espesa de lo real”. En Juan José Saer, Una literatura sin atributos. Santa Fe, Argentina: Universidad Nacional del Litoral, 1988.

Sánchez-Prado, Ignacio. América Latina en la "literatura mundial". Instituto Internacional de Literatura Iberoamericana, Universidad de Pittsburg, 2006.

Soto, Héctor, y Matías Bravo. Entrevista a Roberto Bolaño. Revista Capital, Santiago de Chile, diciembre de 1999. [Recogida en Roberto Bolaño; Andrés Braithwaite (editor), Bolaño por si mismo: Entrevistas escogidas. Santiago de Chile: Ediciones Universidad Diego Portales, 2006].

Steiner, George. Extraterritorial. Ensayos sobre literatura y la revolución lingüistica [1971]. Trad. española de Edgardo Russo. Madrid: Siruela, 2002.

Pasquini, Gabriel. "Entrevista con James Wood". Letras Libres, septiembre 2009.

Zambra, Alejandro. "La poesía de Roberto Bolaño". En Alejandro Zambra, No leer. Crónicas y ensayos sobre literatura. Selección y edición de Andrés Braithwaite. Santiago de Chile: Ediciones Universidad Diego Portales, 2010. 